\title{
PREVALENCE AND ARTERIAL DISTRIBUTION OF STROKE IN TERTIARY CARE HOSPITAL
}

\author{
Ravikumar V1, Senthilvel Murugan V2, Arunraj Ezhumalai ${ }^{3}$
}

${ }_{1}^{1}$ Associate Professor, Department of Neurology, KAPV Government Medical College, Trichy, Tamilnadu, India.

2Professor, Department of Radiology, KAPV Government Medical College, Trichy, Tamilnadu, India.

${ }^{3}$ Senior Assistant Professor, Department of Neurology, KAPV Government Medical College, Trichy, Tamilnadu, India.

\section{ABSTRACT}

\section{BACKGROUND}

Stroke is the number one cause of major disability and the third most common cause of death in the developed and the developing countries. Stroke mortality rises rapidly with age.

The aim of this study was to evaluate the prevalence and arterial distribution of ischemic stroke in a tertiary care hospital.

\section{MATERIALS AND METHODS}

A retrospective descriptive study of 100 cases of ischemic stroke patients who were treated in KAPV Govt. Medical College during the year October 2017 to December 2017. Patients below 20 years of age were not included in our study and venous strokes were excluded from the study.

\section{RESULTS}

Of the total number of 100 ischemic stroke patients, male patients were $66 \%$ and female patients were $34 \%$, most common age group involved was between 51 to 60 (30\%), regarding the arterial territory, anterior circulation (87\%) was more involved than posterior circulation (13\%). Left middle cerebral artery (51\%) was more involved than right MCA (36\%). In right MCA territory in the age group age $>71$, females (16.6\%) were more involved than males. But in the left MCA territory in the age group age $>71$, males were more involved than females.

\section{CONCLUSION}

Ischemic stroke is more common in the males, vulnerable age group affected was 51-60 Yrs. Left MCA was more commonly affected, so morbidity is more common.

\section{KEY WORDS}

Stroke, MRI Findings, Arterial Territory, ACA, MCA, PCA.

HOW TO CITE THIS ARTICLE: Ravikumar V, Murugan SV, Ezhumalai A. Prevalence and arterial distribution of stroke in tertiary care hospital. J. Evolution Med. Dent. Sci. 2018;7(47):5076-5077, DOI: 10.14260/jemds/2018/1128

\section{BACKGROUND}

Stroke is the number one cause of major disability and the third most common cause of death in the developed and the developing countries. ${ }^{1}$ Stroke mortality rises rapidly with age. ${ }^{2}$ Brain blood supply is provided by the two internal carotid and two vertebral arteries which anastomosis at the base of the brain to form the circle of Willis. The internal carotid artery (ICA) bifurcates into the anterior cerebral artery and the larger MCA. The MCA supplies the lateral parts of the cerebral hemispheres. Its lenticulostriate branches supply the basal ganglia and internal capsule. Approximately $80 \%$ strokes are due to ischemic cerebral infarction and $20 \%$ are due to brain hemorrhage. ${ }^{1}$ Among the ischemic strokes 50\% involve the anterior circulation, 25 to the posterior circulation and the remaining $25 \%$ are lacunar infarcts. Occlusion of the MCA usually results from cardio embolism or proximal atherothrombosis.

'Financial or Other Competing Interest': None.

Submission 31-07-2018, Peer Review 31-10-2018,

Acceptance 06-11-2018, Published 19-11-2018.

Corresponding Author:

Senthilvel Murugan $V$,

\#22/B-23, Subham Gardens,

III Block, $6^{\text {th }}$ Main Road,

Srinivasa Nagar,

Vayaloor Road,

Trichy-17, Tamilnadu, India.

E-mail: drsenthilvelmuruganrd@gmail.com

DOI: $10.14260 /$ jemds $/ 2018 / 1128$

\section{Aim}

To study the prevalence and arterial distribution of ischemic stroke in K. A. P. V. Govt. Medical College tertiary care hospital.

\section{MATERIALS AND METHODS}

A retrospective descriptive study of 100 cases of ischemic stroke patients who were treated in KAPV Govt. Medical College during the year October 2017 to December 2017 are included in this study.

\section{Exclusions}

1. All intracranial haemorrhage patients.

2. Age less than 20 years.

3. Venous stoke.

A detailed history was taken at presentation and physical examination was done. In addition to an initial plain CT scan of the brain, to rule out intracranial haemorrhage at presentation, other baseline investigations including ECG, complete blood count, blood sugar, Lipid profile, RFTs were carried out. Echocardiogram, Carotid doppler, CT angiography, magnetic resonance imaging (MRI) and magnetic resonance angiography (MRA) of the brain were performed in selected cases after admission. Age, sex, and arterial territory involvement in all the cases were analysed. 


\section{RESULTS}

Of the total number of 100 ischemic stroke patients, male patients were $66 \%$ and female patients were $34 \%$. Commonest age group involved between 51 to 60 (30\%). Regarding the arterial territory anterior circulation (87\%) was more involved than posterior circulation (13\%). left middle cerebral artery (51\%) was more involved than right MCA (36\%). In right MCA infarct patients age group between 51-60 were more affected in both sexes. In right MCA territory in the age group age $>71$, females $(16.6 \%)$ were more affected than males. But in the left MCA territory in the age group age $>71$, males were more involved than females.

\begin{tabular}{|c|c|c|c|c|c|c|}
\hline Sl. No. & Age & $\mathbf{\%}$ & Male & $\mathbf{\%}$ & Female & $\mathbf{\%}$ \\
\hline 1. & $20-30$ & 6 & 3 & 4.5 & 3 & 8.8 \\
\hline 2. & $31-40$ & 10 & 7 & 10.6 & 3 & 8.8 \\
\hline 3. & $41-50$ & 17 & 15 & 22.7 & 2 & 5.8 \\
\hline 4. & $51-60$ & 30 & 20 & 30.3 & 10 & 29.4 \\
\hline 5. & $61-70$ & 19 & 12 & 18.18 & 7 & 20.5 \\
\hline 6. & $>71$ & 18 & 9 & 13.6 & 9 & 26.4 \\
\hline \multicolumn{7}{|c|}{ Table 1. Age and Sex Distribution } \\
\hline
\end{tabular}

Ischemic stroke is commonest in the 51-60 age group people. In males and females age group between 51-60 were more affected.

\begin{tabular}{|c|c|c|c|c|c|c|}
\hline Sl. No. & Age & $\mathbf{\%}$ & Male & $\mathbf{\%}$ & Female & $\mathbf{\%}$ \\
\hline 1. & $20-30$ & 8.3 & 1 & 4.7 & 2 & 13.3 \\
\hline 2. & $31-40$ & 13.8 & 4 & 19 & 1 & 6.6 \\
\hline 3. & $41-50$ & 13.8 & 5 & 23.8 & - & - \\
\hline 4. & $51-60$ & 33.3 & 7 & 33.3 & 5 & 33.3 \\
\hline 5. & $61-70$ & 13.8 & 3 & 14.2 & 2 & 13.3 \\
\hline 6. & $>71$ & 16.6 & 1 & 4.7 & 5 & 33.3 \\
\hline \multicolumn{7}{|c|}{ Table 2. Incidence of Right MCA Infarct Patients } \\
\hline
\end{tabular}

In right MCA infarct patients age group between 51-60 were more affected in both sexes. In the age group $>71$ females (33.3\%compared to $16.6 \%$ ) were more affected than males. Females were more affected in younger age group between $20-30$ than males ( $13.3 \%$ compared to $4.7 \%$ )

\begin{tabular}{|c|c|c|c|c|c|c|}
\hline Sl. No. & Age & \% & Male & \% & Female & \% \\
\hline 1. & $20-30$ & 3.9 & 1 & 2.7 & 1 & 6.6 \\
\hline 2. & $31-40$ & 7.8 & 3 & 8.3 & 1 & 6.6 \\
\hline 3. & $41-50$ & 23.5 & 10 & 27.7 & 2 & 13.3 \\
\hline 4. & $51-60$ & 29.4 & 10 & 27.7 & 5 & 33.3 \\
\hline 5. & $61-70$ & 17.6 & 6 & 16.6 & 3 & 20 \\
\hline 6. & $>71$ & 17.6 & 6 & 16.6 & 3 & 20 \\
\hline \multicolumn{7}{|c|}{ Table 3. Incidence of Left MCA Infarct Patients } \\
\hline
\end{tabular}

In left MCA infarct patients age group between 51-60 were more affected in both sexes.

\begin{tabular}{|c|c|c|c|c|c|c|}
\hline & Age & $\mathbf{\%}$ & Male & $\mathbf{\%}$ & Female & $\mathbf{\%}$ \\
\hline 1. & $20-30$ & 7.6 & 1 & 11.1 & - & \\
\hline 2. & $31-40$ & 7.6 & - & - & 1 & 25 \\
\hline 3. & $41-50$ & - & - & - & - & \\
\hline 4. & $51-60$ & 23 & 3 & 33.3 & - & \\
\hline 5. & $61-70$ & 38 & 3 & 33.3 & 2 & 50 \\
\hline 6. & $>71$ & 23 & 2 & 22.22 & 1 & 25 \\
\hline
\end{tabular}

Table 4. Incidence of Posterior Circulation Infarct Patients

In Posterior circulation ischemic stroke more common in males compared to females.

\section{DISCUSSION}

Ischemic stroke is more common in the males. Vulnerable age group affected were between 51 to 60. Left MCA was more commonly affected, so morbidity is more common.

It has been found that cerebrovascular disease has a predilection for left side resulting in more frequent left MCA infarctions than infarctions in the territory of the right MCA. The left common carotid artery is a direct branch of the aorta and cardiogenic emboli may prefer left MCA. The hemodynamic differences between the right and left carotid arteries may also result in greater atherosclerotic changes in the left carotid artery leading to more left MCA ischemic strokes. ${ }^{2}$

In our study population, $36 \%$ had right MCA strokes while 51\% had left MCA strokes and 13\% had posterior circulation strokes. Our results are comparable to data from a large hospital-based stroke registry in Germany which revealed that $56 \%$ had left MCA events and $44 \%$ had right sided lesions. ${ }^{3}$ DiLegge et al reported that $59 \%$ of their patients had left MCA ischemic strokes while $41 \%$ had right MCA events.

Ito et al found that among their department-based records of 383 cases between April 2003 and March 2006, $52 \%$ patients had left hemispheric stroke and $48 \%$ had right hemispheric stroke. 4

An increase in carotid artery intima-media thickness (IMT) coincides with risk factors such as hypercholesterolemia, hypertension and diabetes mellitus. It also correlates independently with peripheral atherosclerosis. There exists a difference between IMT of the left and right common carotid artery, with higher values on the left side which may explain predilection for cerebrovascular disease at the left side. 4

\section{CONCLUSION}

The incidence of left MCA territory ischemic strokes is higher than the right MCA distribution in our population. Commonest age group involved was 51-60 Yrs. Males were more commonly affected than females.

\section{REFERENCES}

[1] Feigin VL. Stroke epidemiology in the developing world. Lancet 2005;365(9478):2160-1.

[2] Folsom AR, Eckfeldt JH, Weitzman S, et al. Relation of carotid artery wall thickness to diabetes mellitus, fasting glucose and insulin, body size, and physical activity: Atherosclerosis Risk in Communities (ARIC) Study Investigators. Stroke 1994;25(1):66-73.

[3] Cupini LM, Pasqualetti P, Diomedi M, et al. Carotid artery intima-media thickness and lacunar versus nonlacunar infarcts. Stroke 2002;33(3):689-94.

[4] Ito H, Kano O, Ikeda K. Different variables between patients with left and right hemispheric ischemic stroke. J Stroke Cerebrovasc Dis 2008;17(1):35-8. 